\title{
VIGOREXIA DE LA CULPA
}

\author{
José Antonio Santiago Sánchez ${ }^{1}$ \\ Universidad Complutense (Madrid)
}

http://dx.doi.org/10.5209/rev_NOMA.2012.v36.n4.42310

Resumen.- Parece existir, sobre todo en nuestra contemporaneidad, un cierto prurito muy característico, que tiende a denostar constantemente los fundamentos ideológicos de Occidente. Si bien es cierto que tras la SGM, la caída de la URSS y la reciente crisis financiera, nos hallamos en un periodo de reconfiguración, no obstante, desde algunas corrientes de pensamiento se tiende a una constante y unilateral demonización de la tradición occidental.

Palabras clave.- Crisis, Occidente, culpa, catástrofe

\section{Vigorexia of Guilt}

Abstract.- There seems to be, especially in our contemporary, a very characteristic bias, which tends to constantly insult the ideological foundations of the West. While it is true that after WWII, the fall of the USSR and the recent financial crisis, we are in a period of reconfiguration, however, since some schools of thought tends to a constant and unilateral demonization of the Western tradition.

Keywords.- Crisis, Occident, guilt, disaster

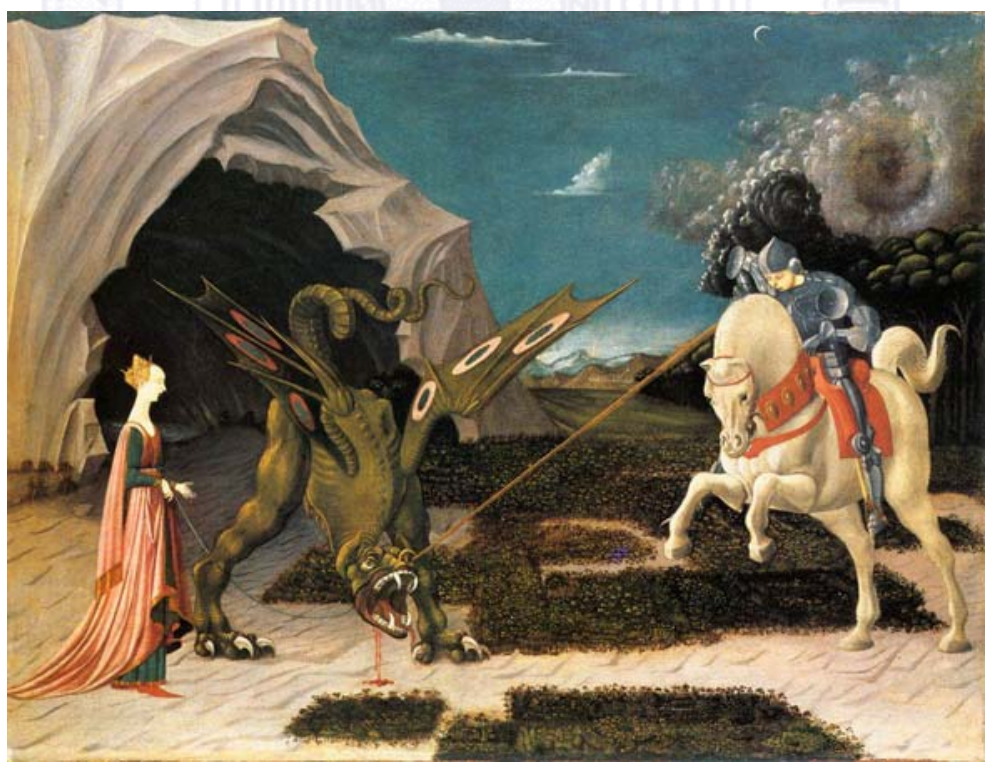

\footnotetext{
${ }^{1}$ Nacido en Madrid en 1976. Doctor en filosofía por la Universidad Complutense de Madrid y profesor de Filosofía y Jefe Departamental en el IES Loustau-Valverde de Cáceres.
} 
1.-

Cuando el director mexicano Arturo Ripstein supo de la existencia del movimiento cinematográfico danés Dogma 95, decidido a recuperar las raíces primitivas del cine, utilizando solo luz natural, cámara al hombro o música diegética entre otros métodos, ${ }^{2}$ solo se ocurrió decir que el dogma llevaba haciéndose en latinoamérica desde hace décadas porque los realizadores carecían de presupuesto para más medios. ${ }^{3}$ No obstante, y a pesar del entusiasmo del director mexicano por los presupuestos revolucionarios de esta nouvelle vague danesa, resultó que solo tras la réplica vanguardista de los realizadores daneses, el público se hizo consciente de que dicha concepción del cine ya había existido antes, sin llegar a ser nunca revolucionaria.

La anécdota viene a colación porque Occidente -la cuna de la Modernidad y en estos momentos, tras el siglo más catastrófico de toda la historia de la Humanidad- se encuentra en un impostergable y evidente proceso de reconstrucción cuya solución parece pasar, en muchos aspectos, por una vuelta al primitivismo de la inocencia.

La ya célebre tesis que Adorno y Horkheimer sostienen respecto a la llustración ha llegado a sentar cátedra en la contemporaneidad: el proyecto ilustrado, con el Progreso, el Individuo y la Razón como estandartes de la Modernidad occidental, contenía en sí mismo el germen de todas las catástrofes del siglo XX. Catástrofes que la época ilustrada jamás llegó a vislumbrar. La Francia de la llustración, la nación más culta de aquel momento, y su paradigma político: el burgués de la Revolución Francesa y la Declaración de los Derechos del Hombre y del Ciudadano era también la que mayores masacres había testimoniado, habiendo además inventado una nueva revolución: la de la guillotina, instrumento por el cual la muerte -ínsita a casi todo proceso revolucionario- deja de concebirse como un espectáculo, eliminando la piedad y el dolor por la rapidez de las ejecuciones. Con la guillotina comienza el proceso de sofisticación de la muerte aplicada: las ejecuciones se hacen más violentas y masificadas al tiempo que menos cruentas y tortuosas.

Ello en verdad mostró cuán terrible puede ser el proceso de civilización. De hecho, los procesos bélicos han constituidos y constituyen los más importantes modos de humanización: desde el imperio español del s. XV, pasando por el inglés del XIX o el de EEUU del pasado siglo XX. Además de ello, y como ocurriera con el ejemplo de la guillotina, la guerra como «arte civilizador» resulta más evolucionada cuanto más tiende a diferenciar lo cruento de lo violento. Las guerras de hoy día no se realizan cruzando espadas y cercenando miembros, ni siquiera disparando desde trincheras; se hacen sobre todo desde el tan fomentado I+D+i, o desde las salas con innumerables botones, así como desde los aviones ultrasónicos. Cuando los estadounidenses lanzaron la primera bomba atómica en 1945 Jaspers dijo que

\footnotetext{
2 En el lenguaje cinematográfico, se denomina música diegética aquella que se está reproduciendo durante la propia narración, a diferencia de la extradiegética, la cual no es

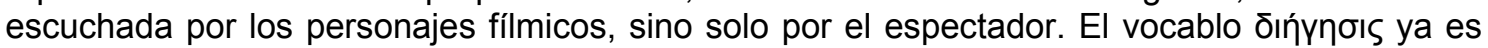
utilizado en la Grecia clásica

${ }^{3}$ «El tape to film o del video al cine» En La Gaceta 11/10/2004. Universidad de Guadalajara. [en línea] http://www.gaceta.udg.mx/Hemeroteca/paginas/363/363-27.pdf
} 
a partir de ese momento la humanidad era libre y creadora, porque podía destruirse. La civilización de los Derechos Humanos se construyó sobre la guillotina del mismo modo a como está sucediendo hoy día. En este sentido, es innegable que el progreso civilizatorio no solo constituye una mejora en las condiciones adaptativas (biológicas, sociales o culturales) de sus miembros, sino que además supone una meritocracia por la que las naciones civilizadas se imbuyen del derecho a colonizar otros territorios.

La tradicional concepción panfilista del humanismo, que entiende lo humano a imagen y semejanza del Creador, ha muerto. La anterior concepción cristiana, posteriormente secularizada, en la que lo humano (como el Progreso o la Cultura) respondía a modelos eminentes, positivos, incluso salvíficos ha dado paso a otra etapa que Peter Sloterdijk ha denominado "posthumanismo». Tan «humana» es la quinta sinfonía de Beethoven como la bomba atómica, tan «cultural» es el botellón («más cultura y menos botellón», decía un alcalde del Norte) como la biblioteca en cuya pared los jóvenes dejan los restos de su peculiar y social libación. En definitiva, tan progresivas son los nuevos tratamientos contra el linfoma a través de células madre como la guerra bacteriológica, capaz de producir muertos, incluso a lo largo de décadas.

Por ello, si la pena de muerte se tilda de procedimiento «inhumano», ello implica subsumir lo humano, no ya a la categoría de bestia (no existe ningún animal capaz de matar con una silla eléctrica o una inyección intravenosa), sino incluso a la de ángel beatífico. Pero el hombre no es un serafín... ni tampoco un demonio. No obstante, este resulta en parte el peligro al que ciertos discursos postmodernistas pueden desembocar. Se trata del peligro de caer en una suerte de fundamentalismo de la culpa, según el cual, el hombre occidental ha generado el sujeto moderno, a su vez de-generado en un ser destructivo, contaminante, impuro y, en definitiva, pecador. ${ }^{4}$

En proporción inversa, cierto pensamiento de corte -diríamos- progresista propugna una alabanza del indigenismo, (sea este el más primario y salvaje) así como una defensa de los animales en virtud de esa sentencia de lord Byron, recogida por Schopenhauer, según la cual «mientras más miro a los hombres, más quiero a mi perro». Dichas corrientes sostienen que "no hay nada en la "cultura occidental" que merezca ser llevado o propuesto o introducido en otras culturas "no occidentales", y afirmar que sí lo hay es la clásica y simple "soberbia occidental" heredera de la mentalidad colonial y conquistadora». ${ }^{5}$

Un ejemplo emblemático traído a colación en la historia de nuestro país es el Descubrimiento de América. Por doquier se plantea la cruel rapiña que, en la formación del Imperio español, los soldados y sacerdotes ejecutaron hacia los indios a partir del siglo XVI, haciéndonos por consiguiente responsables a todos los españoles (de un modo similar a como los actuales alemanes deben sentirse avergonzados del nazismo) de la masacre de los indios y su hábitat a través de sus conquistas y conquistadores. En un libro de Lengua y Literatura

\footnotetext{
${ }^{4}$ Mercedes Ruiz: La secta pedagógica. Madrid: Grupo Unisón, 2003, p. 118.

${ }^{5}$ Rafael Rodríguez Tapia: La enseñanza neutral. Madrid: Grupo Unisón, 1999, p. 107.
} 
de $1^{\circ}$ bachillerato se ilustra el uso del paréntesis con el siguiente ejemplo: «el llamado "Descubrimiento de América" (1492) fue nefasto para los indígenas» ${ }^{6}$

$Y$ sin embargo, pese a las indudables barbaries que pudieron cometer los españoles, es preciso reconocer el papel generador y civilizador que el Imperio Español llevo a cabo en unas poblaciones, ${ }^{7}$ en las cuales algunos de sus miembros (como el famoso ejemplo de la Malinche) apoyaron sin ambages al Imperio, cuya expansión significaba una seguridad y bienestar sin precedentes. A este respecto, es preciso situar en su justo quicio la encomiada figura del fraile Bartolomé de Las Casas, acérrimo defensor de los derechos humanos de los amerindios, pues lo que no se sabe (o se sabe menos) es que Las Casas justificó la esclavitud de los negros con el fin de lograr la liberación de los indígenas americanos. ${ }^{8}$

Pero además, si esto es así, ¿acaso no habría que decir algo similar que personajes tan decisivos como Napoleón o Alejandro Magno? El primero llevó los ideales de la revolución francesa y la llustración a la Europa continental y fue admirado por gentes como Goethe (por no mentar el caso, digamos, más "comprometido» de Nietzsche). El segundo hizo lo propio con la cultura helena hasta casi el Indostán. Si la conquista española de América hubiera sido tan nefasta, ¿no habría que incluir del mismo modo a estos dos grandes personajes en la lista de los más importantes genocidas de la Historia? Otro ejemplo emblemático lo tenemos en Cromwell, el creador de la Commonwealth, el cual llegó a ejecutar al monarca Carlos I el 30 de enero de 1649 (el gran liberal inglés, poco más de un siglo antes, aún no podría haber utilizado la guillotina) para después hacerle coser la cabeza al cuerpo. No obstante, y según recientes encuestas, Cromwell es uno de los diez personajes más importantes para los británicos.

Sin embargo, y si llevamos dichos ejemplos aún más lejos, esta culpa se tornaría aún más desmesurada cuando, por la misma razón, y en tanto especie homo sapiens, todo ser humano debería sentirse responsable de la extinción de los Neandertales, a los cuales el sapiens, mejor adaptado para su movimiento expansivo, sustituyó en el proceso de hominización. Así lo indican las más importantes fuentes paleoantropológicas. ${ }^{9}$ ¿Acaso hace diferente la aniquilación si esta ocurrió hace treinta mil años o si sucedió hace una década?

En el seno del imperio romano, o mejor, en sus catacumbas; clandestino y discriminado, nació el cristianismo. Los que ejecutaron al Mesías, es decir, los enemigos que se afanaron en extinguir Su religión, fueron, con el paso de los años, los que la convirtieron en la religión ecuménica, esto es católica ( $k \alpha Ө o ́ \lambda o u$ significa, como se sabe, "universal»), una vez se legalizó tras el Edicto de Milán (313) y legitimó posteriormente en el primer concilio de Nicea (325) por

\footnotetext{
${ }^{6}$ Mercedes Ruiz: op. cít. P. 144

${ }^{7}$ Vid. Gustavo Bueno. España no es un mito. Madrid. Temas de Hoy, 2005, p. 37 et. alt.

${ }^{8}$ María Teresa González Cortés: «Multiculturalismo y feminismo, un dilema imposible». En El Catoblepas, 52 (2006), p. 14. http://www.nodulo.org/ec/2006/n052p14.htm

${ }^{9}$ Vid. Juan Luis Arsuaga: El collar de neandertal: en busca de los primeros pensadores. Madrid: Debolsillo, 2003. No obstante, recientes investigaciones de la Universidad de Huelva indican que resulta más seguro establecer la hipótesis de tipo ambiental o «agotamiento genético» para explicar las causas de la extinción del Homo Neanderthalensis. (Vid. http://www.20minutos.es/noticia/159116/0/neardental/hombre/extincion/)
} 
Constantino. Por sus calzadas los apóstoles viajaron y llevaron el evangelio urbi et orbi. ¿Cómo situar aquí la culpa?

«Salvaje es aquel que llama a otro salvaje» (Levi Strauss). Bajo esta compasión y tolerancia paternalista por el indígena, dirigida por los discriminadores en proporción inversa a su misma culpa misma, es decir, bajo esta autoflagelación de Europa y la defensa a ultranza de la multiculturalidad a toda costa, se esconde la vigorexia de Occidente, pero sobre todo la soberbia escondida, la cual esconde un etnocentrismo e incluso posturas más peligrosas. Así lo señala la feminista de origen somalí Ayaan Iris Alí:

Lo que estos relativistas culturales no ven es que al mantener temerosamente al margen de toda crítica a las culturas no occidentales, encierran al mismo tiempo a los representantes de aquellas culturas en su atraso. Detrás de todo ello están las intenciones más dispares, pero ya sabemos que el camino al infierno está pavimentado de los mejores propósitos. Se trata del racismo en su acepción más pura. ${ }^{10}$

Por ello, la actitud pretendidamente "progresista»-decíamos- respecto a estas corrientes de pensamiento puede derivar en un peligroso y soberbio gachupinismo de Occidente: el que protege desde la tolerancia pasiva y el relativismo el respeto a los desfavorecidos por su inhumano e inmisericorde desarrollo a lo largo de siglos a costa de los más débiles. Estas corrientes en boga pretenden adoctrinar a los Occidentales utilizando falacias ad populum o ad misericordiam, establecidas, por ejemplo a partir del reduccionismo amo / esclavo, pobre / rico, o bueno / malo (así ocurre en gran medida, por ejemplo, con el conflicto árabe-israelí) y alientan a los ciudadanos, sobre todo en Europa, hacia una «culpa perpetua» que acaso garantice la paz perpetua kantiana tras las catástrofes cometidas en nombre de la civilización. ${ }^{11}$ Así lo señala, en este caso, Oriana Fallaci: «Occidente revela... un odio por sí mismo que es extraño y solo puede ser considerado patológico; Occidente... ya no siente amor por sí mismo, en su propia historia solo ve lo que es deplorable y destructivo, mientras que no percibe lo que es grande y puro» ${ }^{12}$

Lo que aquí resulta importante señalar es el hecho de que, a través de la culpa, la vieja Europa busca su propia fuerza. La fascinación exótica por las otras culturas corre paralela a una constante revisión de las atrocidades de Occidente. $Y$ sin embargo, ¿no resulta este un modo en verdad viciado de seguir mirándose al ombligo? Por ello, y en contra de lo que Fallaci sostiene, en dicha culpa parece verse, por el contrario, una suerte de egolatría sui generis, un amor viciado hacia lo que ya se conoce demasiado, pero no puede dejar de amarse, más propia del resabio de la edad: contigo pero sin ti.

De hecho, resulta interesante comparar esta constante y actual denostación de la civilización occidental respecto a si misma con las tribulaciones que Lutero tenía respecto a su alma en eterna disputa consigo misma, a su constante

\footnotetext{
${ }^{10}$ María Teresa González Cortés: Íbid.

11 No estaría de más apuntar que el mismo promulgador de la paz perpetua, la razón noviolenta y la tolerancia, Inmanuel Kant, fue un firme defensor de la pena de muerte, cosa que se olvida con demasiada frecuencia. (Vid. GARCÍA LÓPEZ, Tomás: «Kant: paz perpetua y pena de muerte». En El Basilisco, 35, (2004), 41-50)

${ }_{12}$ Tunku Varadarajan: «Profeta de la decadencia. Una entrevista con Oriana Fallaci,» En The Wall Street Journal, 23-VI-2005.
} 
énfasis por tomar conciencia del pecado, en su agónica e incansable asunción de sí mismo frente a la ociosidad o la carne: la ocasión es del diablo.

Me veo aquí hundido en la ociosidad, inerte y endurecido, orando poco, no gimiendo nada por la Iglesia de Dios y devorado por las llamas ardientes de mi carne indómita. Resumiendo, yo que debía arder por el espíritu, ardo por la carne, la pasión, la pereza, la ociosidad, la somnolencia... Desde hace ya ocho días no escribo, ni oro, ni estudio, atormentado como estoy a la vez por tentaciones carnales y otros males. ${ }^{13}$

Si por un lado el progresivo adoctrinamiento que el Occidente depredador ejerce respecto a sus ciudadanos política y consumistamente normalizados, otros pensadores parecen estar describiendo en Occidente una naturalización viciada de la sociedad, la cual se utiliza como mecanismo justificador de la dominación occidental. De este modo, posturas denominadas eco-feministas aplican las causas de la culpa de occidente a una excesiva concepción machista y dominadora del Umwelt.

La explicación se basaría en el hecho de que el cisma entre Naturaleza y Dios propio del creacionismo cristiano se somete a una progresiva secularización que toma la forma, antitética ella misma, de espíritu (e incluso "Cultura») frente a Naturaleza. A partir de este paralelismo asimétrico entre lo inmanente y lo trascendente, se situaría el inveterado papel menor de la mujer, situada del lado de la naturaleza, es decir, de la recepción o la pasividad, mientras que el varón se situaría del lado del espíritu (el soplo activo), la dominación cultural y el progreso. De este modo, para la teoría ecofeminista, la tarea consistiría en desnaturalizar los géneros (y no solo los sexos), revisar el tradicional papel del varón-cazador que ha causado muchas de las grandes catástrofes ecológicas y humanas, así como recuperar el valor empático y comprensivo tradicionalmente asociado a la mujer para lograr un «ecologismo de la igualdad».

Y sin embargo, parecen existir en los múltiples ecosistemas del planeta Tierra pruebas que apuntan más a una diversidad e incluso desigualdad, que a una homogeneidad. Leibniz afirmaba en su célebre «principio de identidad de los indiscernibles» que la semejanza absoluta de dos seres pondría en seria duda las facultades propias del Creador. ${ }^{14} \mathrm{Y}$ las propias leyes de la biología evolutiva desde hace siglos nos indican que la desigualdad es evidente por doquier. Lo demás sería situar la naturaleza en el seno del vómos, es decir, de la Cultura o del Espíritu.

\footnotetext{
${ }^{13}$ Martin Luthers Briefwechsel, ed. a cargo de L. Enders, G. Kawerau y Flemming, Frankfurt 1884-1920, Ibid., t. III, p. 189. En Juan A. Echevarría: «Sobre Lutero y sus mentiras». En El Catoblepas, 52, (2006), p. 15. http://www.nodulo.org/ec/2006/n052p15.htm\#kn04

${ }_{14}$ G. W. Leibniz. Discurso de metafísica (\& 9). Versión española de Julián Marías. Madrid: Revista de Occidente, 1942, p. 78.
} 
La teoría cartesiana sobre el automatismo de las bestias, originada en la Edad Media, parte de la imposibilidad de admitir el sufrimiento de los animales, pues si pueden sufrir es que han pecado, lo cual causaría un complejo problema teológico. Dicha teoría, (cuyo antecedente directo, por cierto, es el filósofo pucelano Gómez Pereira y su teoría respecto al «alma de los brutos» ${ }^{15}$ ) resulta un ejemplo radicalmente contrario al bon sens que propugnaba Descartes en su filosofía. Sin embargo, si el ser humano se ha definido en parte desde la devaluación del animal, ¿no estaría sucediendo en estos tiempos el proceso contrario? Pareciera, queremos decir, que el humano ultracivilizado esté domesticando a los animales hasta tal punto que los esté convirtiendo en seres «humanos, demasiado humanos». Se trataría, si esto es así, de un proceso paradójicamente similar al que habría tenido lugar en los albores del neolítico, cuando en una fase religiosa que podríamos denominar "primaria», los humanos prístinos adoraban númenes animales. De hecho, se podría decir con Gustavo Bueno, que «el hombre hizo a sus dioses a imagen y semejanza de los animales» -no a imagen y semejanza del hombre, como decía Feuerbach. ${ }^{16}$

Según la teoría de Bueno, la fase primaria de la religión termina con la domesticación de los animales, pues estos quedan ya inmanentizados e incluso utilizados para la vida cotidiana. De este modo, el animal pierde su carácter extraordinario, su aura numinosa. Lo que podría estar ocurriendo, visto el panorama contemporáneo respecto a los movimientos en defensa de los animales, la prohibición de las corridas de toros o el proyecto Gran Simio sería, paradójicamente, una especie de vuelta a esa religiosidad primitiva que adoraba a los animales, solo que esta vez el proceso habría surgido, no tantodiríamos- por la «convexidad» trascendente ante animales-númenes salvajes respecto al hombre, sino antes bien, por la "concavidad» humanizadora o mimética de los animales respecto del hombre domesticador, sobre todo en el ámbito de las ciudades.

En la tradición polaca existe un cuento infantil que se cuenta a los niños en época navideña: el día de Nochebuena, después de la cena, es tradición compartir en la mesa la ostia consagrada entre todos los familiares. Después, los cabezas de familia han de bajar al establo junto a los niños para dar la ostia a los animales. Sin embargo, tras hacerlo, cuenta la historia, es preciso apresurarse en abandonar el lugar, pues los humanos podrían quedarse allí junto a las bestias por siempre jamás.

En el documental Grizzly Man (2005), el gran director de cine alemán Werner Herzog utiliza el metraje de unas grabaciones domésticas realizadas por Timothy Treadwell, un joven de 32 años, camarero y ex-alcohólico que llegó a ser llamado "el hombre que amaba a los osos». El hecho es que Timothy decidió irse a vivir a los montes de Alaska y compartir el hábitat del oso Grizzly. Ello pese a las advertencias de los guardias del parque natural que le avisan del peligro que para él y para los osos, conllevaría dicha empresa. Gran parte de las grabaciones recopiladas por Herzog insisten en la ferviente creencia de Timothy respecto a la bondad natural de los osos y la inquina de los hombres que solo los quieren para obtener un beneficio económico. Tal es su grado de

\footnotetext{
15 Vid. Eloy Bullón Fernández. El alma de los brutos ante los filósofos españoles. (cap. VI) Oviedo: Biblioteca Filosofía en Español, 2001. http://www.filosofia.org/aut/ebf/alma4.htm

${ }^{16}$ Gustavo Bueno: El animal divino. Oviedo: Pentalfa, 1996, p. 193.
} 
empatía que se atreve a acercarse para convivir con ellos... hasta que es devorado hasta los huesos.

Al final del filme y mientras aparecen unas imágenes de la cara de un oso, el documentalista se pregunta: ¿qué bondad es la que Timothy llegó a ver en esta expresión animal? Y sobre todo, ¿no estará Europa y en general Occidente proyectando la misma alienación no solo en los animales, sino en las culturas del tercer mundo?

Los expertos psicoanalistas analizan el tema del doble como una reacción del sujeto sometido a un amor o a un miedo desmesurado a sí mismo. En ambos casos la respuesta psíquica sería la generación de otro yo idéntico, protector o enemigo. La teoría de Freud es a su vez muy rica, y vincula la aparición del doble a varias etapas de la formación del yo. El doble desdoblado una o varias veces está ligado a la compulsión de repetición, defensiva y ofensiva simultáneamente, común a los niños y al adulto neurótico. El doble como protección contra la muerte pertenece a la etapa infantil en general, mientras que el doble como castración o mutilación se ubicaría más concretamente en la etapa fálica. El doble como conciencia o censura debe situarse en un estado adulto o joven en el que se produce un exceso de superyo que ese doble manifiesta. También en el estado adulto puede generarse el doble como expresión de deseos no cumplidos, y, en fin, como autocastigo que se inflige el yo por la impotencia. ${ }^{17}$

3.-

El médico polaco Andrzej Szczeklik nos relata otra historia tradicional que se cuenta a los niños: un perro entra en una hilera de salas con las paredes completamente cubiertas de espejos. Tras él se cierra la única puerta. El animal permanece parado, rodeado por todas partes de su propio reflejo en los espejos. Muestra sus colmillos, y el resto también, sale corriendo, y ellos detrás. La persecución es cada vez más rápida, ladra cada vez más fuerte, le caen babas cada vez más densas del hocico, hasta que cae agotado y muere.

Pero, ¿qué hubiera pasado si en lugar de abrir sus fauces para mostrar los dientes hubiera meneado el rabo?, ${ }^{18}$ se pregunta Szczeklik. Quizás gran parte de la actitud europea y occidental, incluido en gran medida el talante tolerante y el relativismo, puede explicarse del mismo modo. Acaso en el fondo se trate no más de una inseguridad, patentada en una constante y añeja autoreflexión, en un miedo, e incluso autodesprecio de tantos años que se refleja por momentos

\footnotetext{
${ }^{17}$ Un estudio clásico a este respecto es el del psicoanalista austríaco Otto Rank, uno de los primeros discípulos de Freud en su libro El doble publicado en 1914. (En español El Doble. Buenos Aires: JCE Ediciones, 1992) Las ideas de Rank fueron desarrolladas por Freud especialmente en su ensayo Lo ominoso, pero se englobarían también bajo el etiquetado jungiano de «interpretación analítica». Vid. tmb. Pilar Andrade Boué: «La mitología del doble en Anfitrión 38 de Giraudoux» En Amaltea. Revista de mitocrítica, 0, (2008) UCM, p. 211. http://revistas.ucm.es/index.php/AMAL/article/view/AMAL0808110199A/20633

${ }^{18}$ A. Szczeklik. Coré. Barcelona: Acantilado, 2012, p. 94.
} 
en una admiración u odio (el tránsito es, en el fondo, similar) por lo otro, lo extraño, lo exótico frente a la cual, en un sentido o en otro, Europa se identifica.

Ello tal vez se evidencia más en estos tiempos de crisis, aquellos, en los que, al decir de Gramsci «lo nuevo no termina de nacer y lo viejo no termina de morir». ${ }^{19}$ Tiempos en los que el pensamiento débil tras las catástrofes del siglo XX sueña con volver a la inocencia del buen salvaje rousseauniano, del mismo modo que el Dogma danés respecto al cine primitivo. Tiempos en los que la culpa misma evidencia una vigorexia, una asunción del poder y asimismo, de la enorme responsabilidad que Occidente y sobre todo de la vieja Europa han tenido en tanto protagonistas absolutos de la Historia. De hecho, y tal como señala Walter Benjamin, el capitalismo es probablemente el primer caso de un culto en toda su acepción que no es expiatorio sino culpabilizante. ${ }^{20}$

Pero además, la época capitalista y postcapitalista a la que ha devenido la tradición occidental considera la constante transformación fractal, el recorte, la discontinuidad y lo arbitrario como los modos propios de la temporalidad. Lo permanente en la contemporaneidad es el constante devenir cuyo contenido nunca es el mismo. De este modo, tal vez, la vigorexia de la culpa se postula como un intento escatológico de aferrarse a ese yo prístino y sin culpa, que desde la opulencia ahíta de los contenidos informativos, del Estado del Bienestar, sueña con la pobreza forzada, la menesterosidad. El pensamiento europeo en muchos sentidos se presenta como el rico que quiere ser pobre para gozar más de su riqueza, el "pobre harto de pan» al que solo la intención le vale. En el fondo, Europa solo quiere seguir descubriéndose a sí misma... Y no obstante, escuchemos las palabras de Malebranche:

«Primero, si vieras claramente lo que eres, ya no podrías estar tan estrechamente unido a tu cuerpo. Ya no lo considerarías como una parte de ti mismo... Ya no velarías por la conservación de tu vida... Ya no tendrías víctima para sacrificar a Dios. Segundo, porque la idea de tu alma es tan grande y tan capaz de seducir los espíritus con su belleza que, si vieras claramente la idea de tu alma, ya no podrías pensar en otra cosa... Si tuvieras una idea clara de ti mismo, si vieras en mi espíritu ese arquetipo a cuyo tenor has sido formado, descubrirías tantas bellezas y tantas verdades al contemplarlo que descuidarías todos tus deberes... Absorto en la contemplación de tu ser, lleno de ti mismo, de tu grandeza, de tu belleza, ya no podrías pensar en otra cosa». Para evitar esos dos peligros no me queda más remedio que confesar que «no soy más que tinieblas para mí mismo, que mi sustancia me resulta ininteligible» $^{21}$

\footnotetext{
${ }^{19}$ A. Gramsci. Cuadernos de la cárcel. México D.F: Era, 1981, p. 122.

${ }^{20}$ W. Benjamin: El capitalismo como religión. En Gesammelte Schriften, vol. VI, 100-103. Traducción en http://www.hojaderuta.org/imagenes/elcapitalismocomoreligionbenjamin.pdf

${ }^{21}$ CEuvres X: 104 y OEuvres X: 102 respect. En N. Malebranche: Oeuvres Complètes X, Méditations chretiens et metaphysiques. Paris. J. Vrin, 1986.
} 
4.-

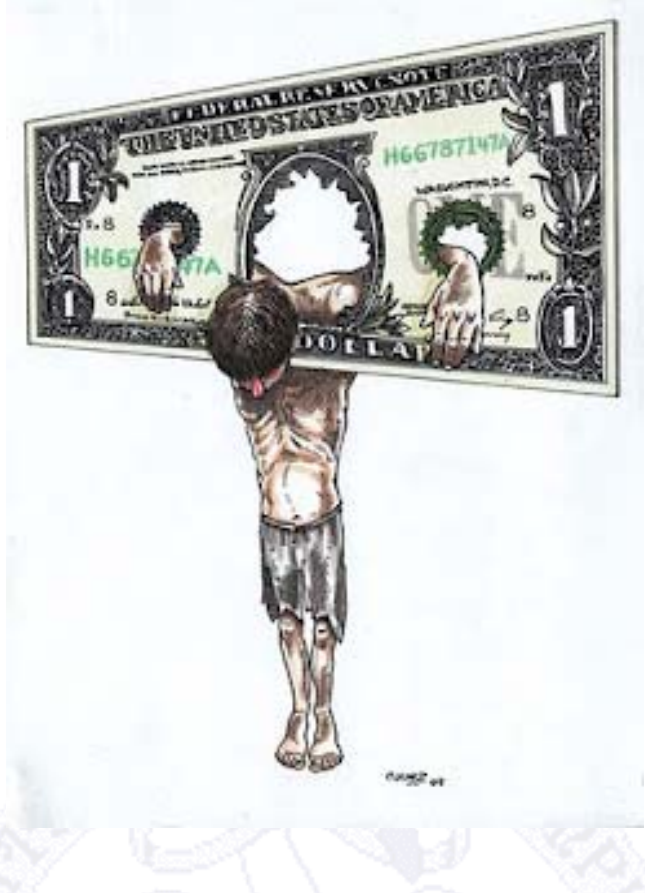

Tal y como, de modo ya clásico, Lyotard diagnostica la época postmoderna, podríamos decir que han sido fundamentalmente tres magnas propuestas (o relatos) las que han caído tras la Segunda Guerra Mundial: una primera gran propuesta tiene su origen en la historia concebida como relato único, un segundo gran relato, es el que genera el ideal de orden y progreso y un tercer gran relato, es de origen positivista, y que promete el bienestar de hombre a través del desarrollo dado en la ciencia y la industria. ${ }^{22}$

No obstante, el acelerador de partículas del CERN o la descodificación del genoma humano, ambos descubrimientos acaecidos en la última década, se encuentran entre los grandes hitos de la historia de la Humanidad. ¿En verdad terminaron los grandes relatos? Acaso el «pensamiento débil» no sea sino un retruécano modal para constatar el propio poder 0 superioridad del pensamiento occidental. Desde el cartesianismo hasta el existencialismo, el sujeto (sobre todo en tanto in-dividuo) ha ido surgiendo e imponiéndose en el panorama de la filosofía occidental. Se trata de un proceso que, aunque se olvida, el cristianismo ya lo constata haciendo del Hombre el centro de la Creación. Dicho proceso, establecido a partir de formas contemporáneas de pensamiento como el estructuralismo o la postmodernidad intentan diseminar (en el sentido de Derrida) toda la modernidad y asumir las consecuencias de su catástrofe, diluyendo el humanismo antropocéntrico, explotador y subjetivista. A este respecto, el posthumanismo se caracterizaría por una superación del humanismo proveniente del Renacimiento clásico. Se trata de una asunción de las limitaciones de la otrora omnímoda racionalidad humana, la cual ha propiciado para Sloterdjik, una serie de «fundamentalismos filosóficos» como el cristianismo, el marxismo o el existencialismo; sólidos e incontrovertibles

\footnotetext{
${ }^{22}$ Passim J. F. Lyotard: La condición posmoderna, Madrid, Cátedra, 1994.
} 
sistemas los cuales han impedido que se dude de los conceptos que presuponen. Según Sloterdijk la metafísica ha seguido una estrategia igualmente perversa: generar la sensación de un vacío (de una culpa, podríamos decir) y al mismo tiempo imponer la necesidad de cubrirlo con la emergencia del sujeto. ${ }^{23}$

Esta nueva era que Sloterdjik propone, liberada de la razón domesticadora y unilateral, del sujeto y del humanismo sería aquella en la que cualquier sentido estaría infinitamente abierto (Derrida) y, por lo tanto, cualquier punto externo al hombre podría ser legítimamente asible. Una era de la xenolatría, de amor y fascinación por lo extraño solo por ser un «otro», incluidos los animales, las máquinas o las plantas... a los que el egocentrismo de la filosofía occidental ha mascarado e incluso masacrado a través de la razón, primero sustancial (Grecia) y luego instrumental (Modernidad). Un pensar tan abierto como hasta entonces jamás había existido. Una vuelta a la niñez que combata el hastío de Occidente que solo se satisfizo con lo que Hegel llamaba la «furia de la desaparición», un regreso a la descivilización, una desconstrucción hacia el «futuro primitivo». ${ }^{24}$

\section{Conclusión.}

La culpa de occidente ha obligado a través del siglo $X X$ a deshumanizar lo que dos siglos antes había sido una humanidad del Progreso y la Luz, el Orden y la Civilización. Ahora solo queda mirar a los indigentes y los explotados, "los únicos -afirma Steiner- que pueden estar seguros de su humanidad». ${ }^{25} \mathrm{Y}$ es que todo eso que caracterizaba la civilización: la educación y las formas, la alta cocina, la tecnología y cibernética, la ópera y los perfumes... pero también la guillotina, la silla eléctrica, la bomba atómica, la guerra bacteriológica... ha sido deslegitimado. Tanto unos rasgos como otros han hecho perder la humanidad "por exceso», precipitando el pensamiento hacia un nihilismo que manifiesta, desde el relativismo y la hipercrítica, desde la culpa y la tolerancia universales, la falsa impotencia y debilidad del pensamiento occidental. Todo ello se explica, en palabras de Isidoro Reguera, debido al aburrimiento que Occidente padece desde lo que Sloterdjik ha ven ido en llamar el "palacio de cristal»:

En el palacio de cristal reinan dos sensaciones globalizadas: al aburrimiento (posthistórico: ya ha acabado todo, no hay nada que hacer) y el estrés (postmoderno autogenerado graciosamete entre todos para no aburrirse (...)) si

\footnotetext{
${ }^{23}$ A. Vásquez Rocca: «Peter Sloterdijk; el posthumanismo: sus fuentes teológicas y sus medios técnicos». En Observaciones Filosóficas, 3 (2006) http://www.observacionesfilosoficas.net/posthumanismo.html

${ }^{24}$ Filósofo calificado de «primitivista», el estadounidense John Zerzan critica en sus obras a la civilización como inherentemente opresiva, defendiendo como alternativa la vuelta a una suerte de anarquismo establecido por formas de vida prehistóricas. Sus críticas se extienden a la domesticación de los animales o al pensamiento racional tal y como se ha considerado desde los griegos. A este respecto, resulta especialmente interesante su crítica al lenguaje matemático en tanto lenguaje del poder calculador y dominador propio de Occidente. (Vid. John Zerzan: Futuro primitivo y otros ensayos. Valencia: Numa, 2001.)

${ }^{25}$ G. Steiner. La poesía del pensamiento. Madrid: Siruela, 2012. p. 104.
} 
quiere uno liberarse de esa tontuna del palacio no tiene más que una solución terrorista (...) romper el cristal y con él toda la estructura palaciega su aburriente estrés y su estresante aburrimiento $(\ldots)^{26}$

En este sentido, cabría corresponder esta, por momentos, mala fe del pensamiento europeo contemporáneo y su asunción histórica a través de la culpa con el episodio de María de Betania que se narra en Mateo 26, 3-13; y ello asimismo por el hecho de que, a partir de dicho suceso, Judas toma la decisión definitiva de traicionar a Jesús. Recordemos la historia: Jesús se encuentra en la casa de Simón el leproso, en Betania; se le acerca una mujer con un frasco de alabastro, con aceite perfumado muy precioso, y se lo derrama en la cabeza mientras está a la mesa. "Al ver esto los discípulos, se indignaron y decían: ¿A qué viene este despilfarro? Pudo venderse a gran precio, y darse a los pobres. Jesús se dio cuenta y les dijo: ¿Por qué molestáis a esta mujer? Ha hecho una buena obra conmigo. Pues siempre tendréis pobres con vosotros, pero a mí no me tendréis siempre. Al derramar este ungüento sobre mi cuerpo, lo ha hecho para mi sepultura. En verdad os digo que donde sea predicado este evangelio, en todo el mundo, se hablará también de lo que está ha hecho, para recuerdo suyo».

Este quizá sea el mismo reto que habría que asumir ante el «pensamiento débil». Es el reto al que tal vez - nos atrevemos a proponer - deba hacer frente la filosofía, (y no tanto el "pensar») en un tiempo que no es ya el de las «minorías selectas» sino el de las nuevas mayorías, ya no compiladas en masas, sino ilustradas y preparadas operatoriamente como nunca. «En cualquier caso - y como señala Jacobo Muñoz- el triunfo final que algunos auguran, y en el que parecen complacerse, de un mundo "posfilosófico" -y, en consecuencia, carente de toda dimensión crítica y autorreflexiva relevantesería el triunfo de una de las más lúgubres de esas utopías negativas que proliferaron, y no sin razón, a lo largo del pasado siglo». ${ }^{27}$

Siempre hubo guerras y crisis. $Y$ nunca dichos acontecimientos dieron lugar a mejores tiempos. No obstante, está en nuestra mano que las catástrofes de antaño hayan sido y sean verdaderamente superadas, para no caer de nuevo, quién sabe, en el mismo peligro que las ocasionó. Quizás esa superación histórica, esa síntesis, la Aufhebung, solo pueda llegar como tituló Jean Améry -una víctima de Auschwitz- una vez se haya alcanzado un tiempo «más allá de la culpa y la expiación».

\footnotetext{
${ }^{26}$ «Conocimiento y hedonismo: el relato de la felicidad» En Paradoxa 14 (2011) p. 29. Vid. tmb. P. Sloterdijk: «El Palacio de Cristal», Conferencia pronunciada en el marco del debate "Traumas urbanos; La ciudad y los desastres", Centro de Cultura Contemporánea de Barcelona, CCCB. 2004, pp. 11-19. http://www.cccb.org/rcs_gene/petersloterdijk.pdf

${ }_{27} \mathrm{~J}$. Muñoz. «Necesidad de la filosofía». En Observaciones Filosóficas 1, (2005) [en línea] http://www.observacionesfilosoficas.net/necesidadfilosofia.htm
} 


\section{Bibliografía}

(2008) ANDRADE B, Pilar: «La mitología del doble en Anfitrión 38 de Giraudoux» En Amaltea. Revista de mitocrítica, 0, Madrid.

http://revistas.ucm.es/index.php/AMAL/article/view/AMAL0808110199A/20633

- (2003) ARSUAGA, Juan Luis: El collar de neandertal: en busca de los primeros pensadores. Madrid: Debolsillo.

Ruta,

(2008) BENJAMIN, Walter: El capitalismo como religión. En Hoja de

http://www.hojaderuta.org/imagenes/elcapitalismocomoreligionbenjamin.pdf

- $\quad$ (1996) BUENO, Gustavo: El animal divino. Oviedo: Pentalfa.

- $\quad$ (2005) BUENO, Gustavo: España no es un mito. Madrid: Temas de Hoy.

- (2001) BULLÓN F. Eloy: El alma de los brutos ante los filósofos españoles. Oviedo: Biblioteca Filosofía en Español.

http://www.filosofia.org/aut/ebf/alma4.htm

(2006) ECHEVARRIA, Juan A: "Sobre Lutero y sus mentiras». En El Catoblepas, 52, p. 15. http://www.nodulo.org/ec/2006/n052p15.htm\#kn04

(2004) GARCÍA LÓPEZ, Tomás: «Kant: paz perpetua y pena de muerte». En El Basilisco, 35, pp. 41-50.

- (2006) GONZALEZ CORTES, Ma . Teresa: «Multiculturalismo y feminismo, un dilema imposible». En El Catoblepas, 52, p. 14.

http://www.nodulo.org/ec/2006/n052p14.htm

- (1981) GRAMSCI, Antonio: Cuadernos de la cárcel. México D.F: Era.

Occidente.

(1942) LEIBNIZ G. W. Discurso de metafísica. Madrid: Revista de

(1994) LYOTARD J. F.: La condición posmoderna, Madrid, Cátedra. 
(1986) MALEBRANCHE Nicolas: Oeuvres Complètes X, Méditations chretiens et metaphysiques. Paris. J. Vrin.

(2005) MUÑOZ, Jacobo: «Necesidad de la filosofía». En Observaciones Filosóficas 1, http://www.observacionesfilosoficas.net/necesidadfilosofia.htm

- (2011) REGUERA, Isidoro: «Conocimiento y hedonismo: el relato de la felicidad» En Paradoxa 14, pp 24-29.

(2004) RIPSTEIN, Arturo. «El tape to film o del video al cine» En La Gaceta. Universidad de Guadalajara.

http://www.gaceta.udg.mx/Hemeroteca/paginas/363/363-27.pdf

- (2003) RUIZ, Mercedes: La secta pedagógica. Madrid: Grupo Unisón.

- (1999) RODRIGUEZ TAPIA Rafael: La enseñanza neutral. Madrid: Grupo Unisón.

- $\quad$ (2012) STEINER, Georg: La poesía del pensamiento. Madrid: Siruela.

- $\quad$ (2012) SZCZEKLIKJ Andzrej, Coré. Barcelona: Acantilado.

- (2006) VÁSQUEZ ROCCA Antonio: «Peter Sloterdijk; el posthumanismo: sus fuentes teológicas y sus medios técnicos». En Observaciones Filosóficas,

3.

http://www.observacionesfilosoficas.net/posthumanismo.html

- (2001) ZERZAN, John: Futuro primitivo y otros ensayos. Valencia: Numa. 